Research Article

\title{
The Design of Teaching Evaluation and Organization System Based on the Internet of Things Using Fuzzy Comprehensive Evaluation Software
}

\author{
Hang Guo \\ School of Education Science, South China Normal University, Guangzhou, Guangdong 510631, China \\ Correspondence should be addressed to Hang Guo; 2016010049@m.scnu.edu.cn
}

Received 26 September 2021; Revised 15 October 2021; Accepted 18 October 2021; Published 30 November 2021

Academic Editor: Fazlullah Khan

Copyright (C) 2021 Hang Guo. This is an open access article distributed under the Creative Commons Attribution License, which permits unrestricted use, distribution, and reproduction in any medium, provided the original work is properly cited.

\begin{abstract}
Educational evaluation is the main method of modern education management and guidance. Through a systematic collection of information and quantitative and qualitative analysis, value judgments can be made on the degree to which education adapts to needs, which can effectively improve the teaching development of applied undergraduate colleges. This article applies the Internet of Things technology to the information collection process of teaching evaluation in applied undergraduate colleges. This paper establishes an Internet of Things architecture to collect information on the impact indicators of the teaching evaluation process and builds a teaching evaluation index system. On this basis, this article combines fuzzy comprehensive evaluation for the quantification and evaluation process of index information. Through comparative analysis, the program can provide an effective way to construct a teaching evaluation system suitable for application-oriented undergraduate colleges. Constructing the research-based undergraduate classroom teaching evaluation index system aims at guiding the transformation of the concept of teaching and learning of teachers and students in research universities, perfecting the teaching and learning methods, improving the quality of teaching and learning, and promoting the common development of teachers and students.
\end{abstract}

\section{Introduction}

Teaching quality evaluation, as an important aspect of education evaluation in applied undergraduate colleges, is to judge the value of teaching phenomena and evaluate the performance of teaching activities $[1,2]$. It is both the core and the foundation of educational evaluation. Specifically, it is the process of making judgments on the quality of teaching based on systematically, scientifically, and comprehensively collecting, sorting, processing, and analyzing teaching information according to teaching goals and standards [3].

Many universities in the world such as Oxford, Cambridge, and Imperial College in the United Kingdom, Harvard University in the United States, and famous universities in Germany, France, Japan, and other countries give importance to the investigation and evaluation of the school's internal teaching information. Department and various disciplines and majors have a relatively standardized evaluation system [4]. An Angelo of Boston College first proposed the relevant content of classroom teaching evaluation, which is mainly about using classroom teaching evaluation as a strategy to improve the quality of college teaching [5]. Since then, some related works and achievements have appeared continuously in the United States. For example, there is the Perdue Teaching Grade Rating Scale, which is mainly used to collect students' rating scales for evaluating teachers' teaching information. Dr. Contra of the American Education Service Center proposed that good classroom teaching should have eight characteristics.

Definitions of teaching evaluation are as follows.

There are many definitions of teaching evaluation [6]. 
(i) American educational evaluation scholars Taylor Ralph Taylor and Malcolm Proves believe that "teaching evaluation is a process of comparing actual performance with ideal goals" [7]. This point of view has some truth because, in teaching evaluation work, it is often to compare the actual situation with the ideal goal, but this definition only describes the evaluation of the completed behavior and does not include the formation process $[8,9]$.

(ii) However, DL Stufflebeam, Warthin, and Sanders believe that teaching evaluation is "a process of systematically searching and collecting information to assist decision-makers in choosing one of the various feasible ways." This view has won the majority of people [10-12].

1.1. Evaluation Index. The evaluation index system for experts mainly includes teaching materials and teaching progress, teaching content, basic teaching skills, teaching links and teaching methods, classroom organization and teaching management, and teaching and educating people. The evaluation content is used for expert evaluation.

With the increasing standardization of teaching management, the role of teaching evaluation as a quality diagnosis and control method is becoming more and more important. Through evaluation, the school's teaching management can be promoted to be more scientific and standardized, which is the main measure and effective means of macrocontrol teaching [13].

1.2. Modern Management Theory. This theory emphasizes target control, process control, and element control. The key to achieve optimal control lies in information feedback. Educational evaluation is the main method of modern education management and guidance. Through a systematic collection of information and quantitative and qualitative analysis, value judgments can be made on the degree to which education adapts to needs. This article applies the Internet of Things technology to the information collection process of teaching evaluation in applied undergraduate colleges. Through the assessment of teaching quality, we can provide multichannel and comprehensive feedback of the most basic information from all aspects of teaching so that the school can objectively grasp the current situation and level of teaching activities and understand whether the teaching strategies and management methods are correct.

The major contributions of this paper are as follows:

(1) This article combines the teaching status of colleges and universities and related problems in teaching evaluation.

(2) It establishes an Internet of Things architecture to collect information on the impact indicators of the teaching evaluation process and builds a teaching evaluation index system.

(3) The teaching evaluation model is based on the fuzzy comprehensive evaluation that leads the fuzzy method into the teaching evaluation. A fuzzy comprehensive evaluation is carried out on the index system of teaching evaluation, and the evaluation results are obtained.

The outline of this paper is given as follows.

In section 2, architecture design of teaching evaluation based on the Internet of Things is discussed. Also the application fields of the Internet of Things are discussed.

In section 3, the teaching quality evaluation index system is discussed, which aims to provide quality education for all students. In the teaching evaluation index system, they are more focused on the teacher's overall quality, assessing the teacher's background, knowledge, feedback, communication, and self-learning.

In section 4 , the evaluation scale of the evaluation index system is discussed. A fuzzy comprehensive evaluation is carried out on the index system of teaching evaluation, and the evaluation results are obtained. Also, the internal teaching quality monitoring system for colleges and universities is discussed.

\section{Related Work}

2.1. Architecture Design of Teaching Evaluation Based on the Internet of Things. The application fields of the Internet of Things are very wide. According to network availability, coverage, scale, heterogeneity, repeatability, and so on, applications in various fields can be classified $[14,15]$. In the above application fields, the IoT as the main form of data acquisition, the application of cloud computing, and the process of big data provides more intelligent equipment identification, management, and monitoring work, which will be hidden in the future development with great potential [16]. This article applies the Internet of Things technology to the information collection process of teaching evaluation in applied undergraduate colleges. This paper establishes an Internet of Things architecture to collect information on the impact indicators of the teaching evaluation process and builds a teaching evaluation index system. Figure 1 depicts a schematic diagram of the basic architecture of the Internet of Things technology.

Different IoT network structures have appeared in various industries, and they all have common capabilities, including device access, management, and data communication between devices and the cloud [17]. In the industry chain of the Internet of Things, some software platforms containing these common core functions have also appeared. Based on this software platform, developers avoid the repetitive work of building the underlying architecture and can develop applications more conveniently and flexibly according to different business needs, which saves precious time and energy. Software platform is similar to this.

\section{Methods}

In this section, the teaching quality evaluation index system is discussed, which aims to provide quality education for all students. In the teaching evaluation index system, they are more focused on the teacher's overall quality, assessing the 


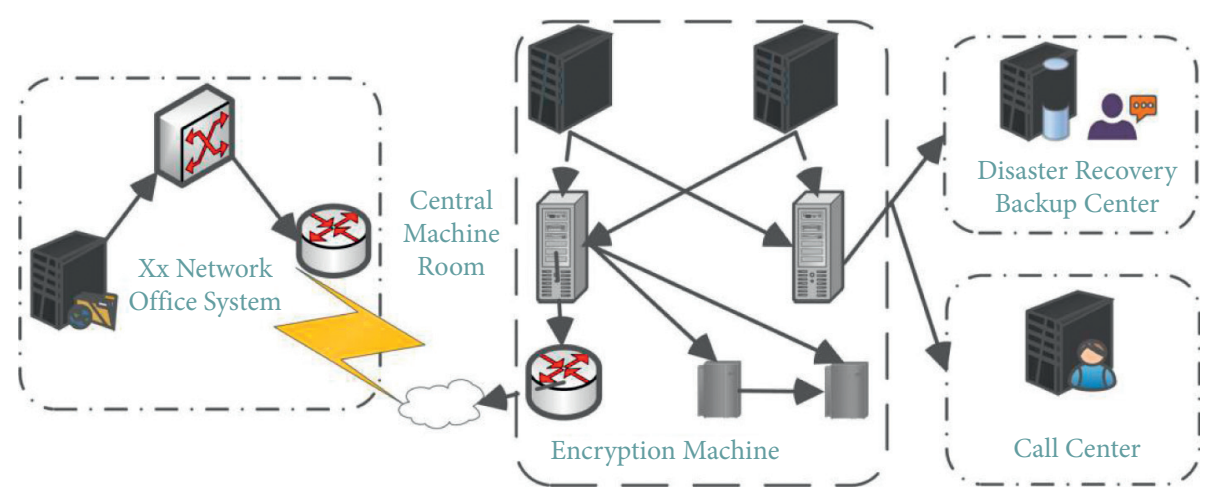

Figure 1: Schematic diagram of the basic architecture of the IoT.

teacher's background, knowledge, feedback, communication, and self-learning.

\subsection{Construction of Teaching Quality Evaluation Index} System. Generally, the conventional indexes of educational institutes include teaching attitude, school discipline, teaching content, teaching methods, and so on. These indexes only can unilaterally monitor classroom teaching, but they cannot qualitatively analyze and assess the teacher's overall performance and innovation capability. The developed countries like the United States, England, and Germany focused more on teaching quality evaluation. They are more focused on the teacher's innovation capability and emphasized on the teacher's ability to guide students to find, analyze, and solve problems. Second, they attach importance to the teacher's overall quality, assessing the teacher's background, knowledge, feedback, communication, and self-learning.

Teaching evaluation mainly assesses whether teachers conduct comprehensive quality education for all students in teaching and whether they attach importance to ability training, so that students can master learning skills and have the ability to independently acquire knowledge $[18,19]$. As an important tool for the classroom, the abovementioned content can be evaluated very well, but the usually determined index system cannot be a very good and comprehensive investigation of specific content.

Applied undergraduate colleges mainly cultivate practical talents for all walks of life in society, so teachers should not only teach theoretical knowledge but also focus on cultivating students' practical ability when teaching, so teachers' practical guidance to students is particularly important $[20,21]$. However, the current teaching evaluation index system used by schools mainly measures teachers' theoretical teaching levels. The existing teaching evaluation index system only focuses on explicit behavior. For example, the design, implementation, application, and promotion of the teaching evaluation index system only reflect superficial things. Those invisible behaviors, such as the teacher's attitude in the classrooms with the students in the teaching process, are difficult to be reflected, so some emotional factors in the teaching process cannot be truly revealed [22].
This article combines the teaching status of colleges and universities and related problems in teaching evaluation. Under the guidance of experts, according to the comprehensive needs of teaching evaluation, we screen out various evaluation indicators to initially construct in colleges. For the classroom teaching quality evaluation index system, using two rounds of expert consultation methods, finally, an evaluation index system is evolved [23,24]. Figure 2 shows a schematic diagram of the self-monitoring system for teaching quality evaluation.

According to the different subjects of teaching evaluation, the evaluation index system for students and system for experts (mainly referring to the teaching supervision group experts and peers of various colleges and universities) have been established $[25,26]$.

3.2. Evaluation Index System for Teachers. The evaluation index system for experts mainly includes teaching materials and teaching progress, teaching content, basic teaching skills, teaching links and teaching methods, classroom organization and teaching management, and teaching and educating people. The evaluation content is used for expert evaluation. The indicator system is refined into 23 secondary indicators.

3.3. Evaluation Index System for Students. It mainly includes teaching links and teaching methods, basic teaching skills, classroom organization and teaching management, and teaching and educating people. The index system for student evaluation is refined into 24 secondary indexes.

3.4. Fuzzy Comprehensive Evaluation. The teaching evaluation model is based on the fuzzy comprehensive evaluation that leads the fuzzy method into the teaching evaluation. The teaching evaluation is a complicated process with multifactor and multi-indicator which cannot be distinguished accurately. Fuzzy logic is a method whose greatest feature is that it can deal in a precise manner with the fuzziness of the thinking of a human. However, it still adopts the method man-made to set the index weights, and its computation is subjective. 


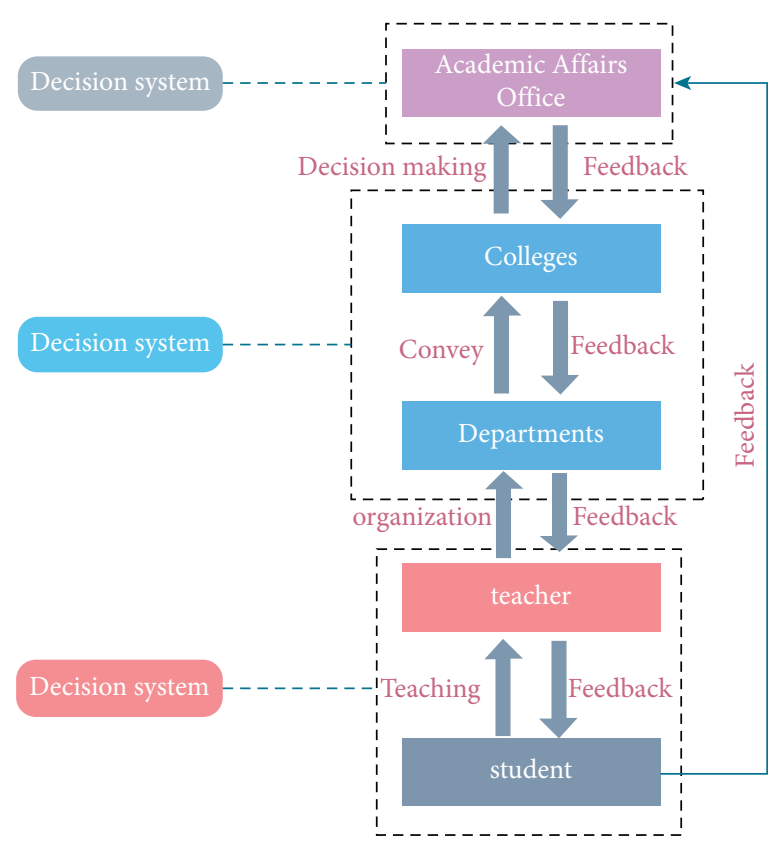

Figure 2: Schematic diagram of the self-monitoring system for teaching quality evaluation.

The fuzzy comprehensive evaluation method can more comprehensively summarize the opinions of each evaluation subject and comprehensively reflect the pros and cons of the evaluated object. It has the advantages of a simple model, easy to grasp, and good evaluation effect on multilevel and multifactor complex issues $[27,28]$. The research can choose the above models according to actual needs. The weighted average method considers that each item in the evaluation system should be treated differently; that is, different factors have different positions in the evaluation and their roles are different, and the weights assigned to them should not be the same $[29,30]$.

This method can avoid the distortion of the evaluation results because of only considering the dominant role played by subjective factors in the comprehensive evaluation. Therefore, in the research process of this article, a weighted average model is adopted.

$$
h_{\theta}(t)=g\left(\theta^{T} t\right)=\frac{1}{1+e^{-\theta^{T} t}} .
$$

After the grade is assigned, the evaluation scale of the evaluation index system is established and sent to the experts for scoring [31]. The expert group scores are entered into the Yaahp 10.3 software for calculation, and the consistency of the judgment matrix at the criterion level is less than 0.1, indicating that the matrix has high consistency, the matrix is established, and the criterion level weight is obtained.

$$
\begin{aligned}
Q(x, q)=\frac{f}{f_{0}}+\sum_{j} p_{x}\left(x_{j}\right)+q\left[\sum_{j} p_{g}\left(g_{j}\right)+\sum_{j} p_{h}\left(h_{j}\right)+\sum_{j} p_{w}\left(w_{j}\right)\right] . \\
D\left(v_{0}\right) \leq D\left(v_{1}\right) \leq D\left(v_{2}\right) \leq \cdots \leq D\left(v_{n}\right) .
\end{aligned}
$$

This paper uses the same method to calculate the corresponding weights of the scheme layer through Yaahp 10.3 software and checks the consistency of the judgment matrix of the scheme layer. The consistency test of all the judgment matrices is less than 0.1. At the same time, the weight of each scheme layer is calculated and the level single ordering is performed [27].

$$
x^{(j+1)}=x^{(j)}+s_{j} d^{(j)} .
$$

The index weights obtained by the single-level ranking are sorted to obtain the total ranking of the levels, and then a complete teaching evaluation index system is obtained.
According to the general principles of fuzzy comprehensive analysis, the comment set is established, and $n=3$ is selected in this article. According to the content of the comment set, the evaluation criteria are quantitatively assigned, and the difference is decreased according to the degree of praise.

$$
D(v)=\sum C\left(v_{i}, v_{j}\right), \quad \text { where } v_{i}, v_{j} \in V .
$$

Based on the weight vector of each index obtained by the AHP method, the fuzzy membership matrix $R$ between each evaluation factor and evaluation level is established. The 
specific method is by issuing questionnaires related to specific cases.

$$
D\left(v_{n+1}\right)=\min \left\{D\left(v_{n}\right)+C\left(v_{i}, w\right)\right\}, \quad \text { where } v_{i} \in U, w \in V-U .
$$

First, grade judgments are made on all factors in the secondary indicators in this case, and the questionnaire is sorted out.

$$
\begin{aligned}
& d^{\prime}(t, x)=\sum_{j}^{N_{p}} \mu\left(\tau=t-p_{j} x, p_{j}\right) \Delta p_{j}, \\
& \mu(\tau, p)=\int_{-\infty}^{+\infty} d(t=\tau+\mathrm{px}, x) \mathrm{d} x .
\end{aligned}
$$

Second, using the index weight vector that has been obtained, it is transformed into a weight matrix, the fuzzy membership matrix is synthesized, and the first-level evaluation factor fuzzy matrix is carried out. This method can avoid the distortion of the evaluation results because of only considering the dominant role played by subjective factors in the comprehensive evaluation.

\section{Results}

In this section, the evaluation scale of the evaluation index system is discussed. A fuzzy comprehensive evaluation is carried out on the index system of teaching evaluation, and the evaluation results are obtained. Also, the internal teaching quality monitoring system for colleges and universities is discussed. Its main function is to be responsible for the quality assurance of colleges and universities.

4.1. Evaluate Test Results. This paper establishes an Internet of Things architecture to collect information on the impact indicators of the teaching evaluation process and builds a teaching evaluation index system. On this basis, this article combines fuzzy comprehensive evaluation for the quantification and evaluation process of index information. Through comparative analysis, the program can provide an effective way for application-oriented undergraduate colleges. A fuzzy comprehensive evaluation is carried out on the index system of teaching evaluation, and the evaluation results are shown in Figures 3 and 4 . Figure 3 shows the category distribution results of the evaluation indicators.

It can be seen from Figures 3 and 4 that the evaluation scale of the evaluation index system is established and sent to the experts for scoring. The expert group scores are entered into the Yaahp 10.3 software for calculation, and the consistency of the judgment matrix at the criterion level is less than 0.1 , indicating that the matrix has high consistency, the matrix is established, and the criterion level weight is obtained. Figure 4 depicts the consistency test results of different evaluation indicators.

This method can avoid the distortion of the evaluation results because of only considering the dominant role played by subjective factors in the comprehensive evaluation. Among them, the evaluation index system for experts mainly includes teaching materials and teaching progress, teaching

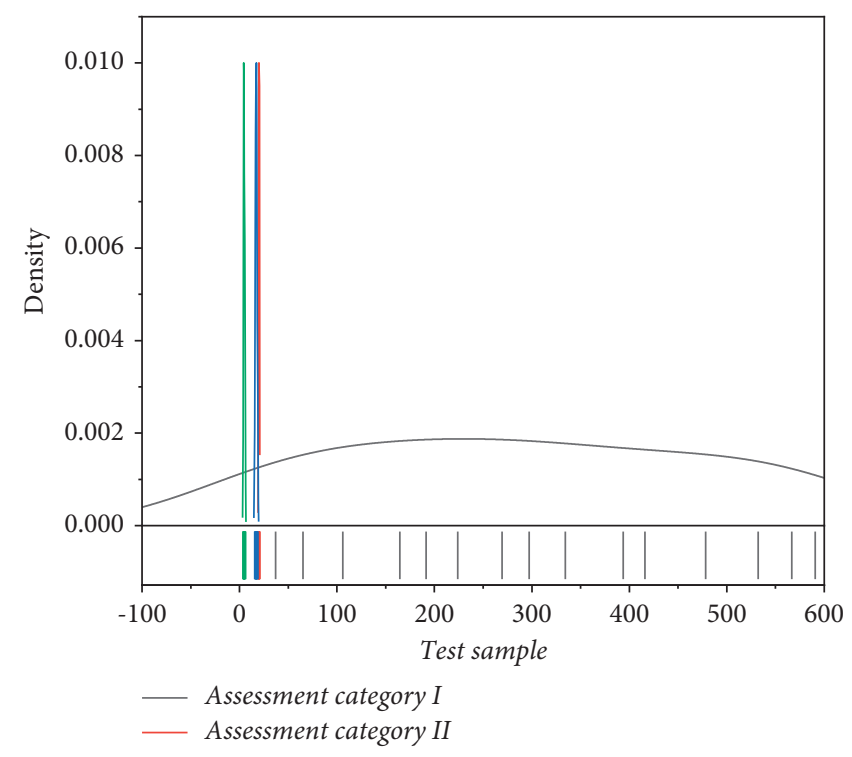

FIgURE 3: Results of category distribution of evaluation indicators.

content, basic teaching skills, teaching links and teaching methods, classroom organization and teaching management, and teaching and educating people. The evaluation content is used for expert evaluation. The quality of teaching is the lifeline of the school's survival and development, and teaching is the regular central task of the school. Classroom teaching is the main way of teaching activities; its level and quality are directly related to the final effect of teaching work and talent training. Therefore, a comprehensive and comprehensive analysis of the quality and effective control of various influencing factors through scientific and reasonable evaluation methods have important practical significance for improving quality and achieving the goal of talent training.

4.2. Evaluation and Organization System. The internal teaching quality monitoring system is the teaching quality monitoring system of colleges and universities. Its main function is to be responsible for the quality assurance of colleges and universities. It has different characteristics for different schools. Among them, "white monitoring" and "other monitoring" are two basic forms of quality assurance. "White monitoring" refers to the teaching operation system, that is, the supervision of the teaching operation process and teaching quality, and the "other monitoring" refers to the system that the evaluation and supervision system monitors the teaching quality. This system plays the role of teaching quality monitoring outside the teaching operation system. Figure 5 is the collaborative cooperation model of "selfmonitoring" and "other monitoring."

The systematic cooperation in the process is mainly manifested in the benign interaction between the teaching guidance groups of the colleges and the teaching operation institutions. Each college is the executive body of the teaching operation system, and the teaching steering group is the executive body of the evaluation and supervision system in each college. The benign interaction between the two is an important manifestation of the coordination and 


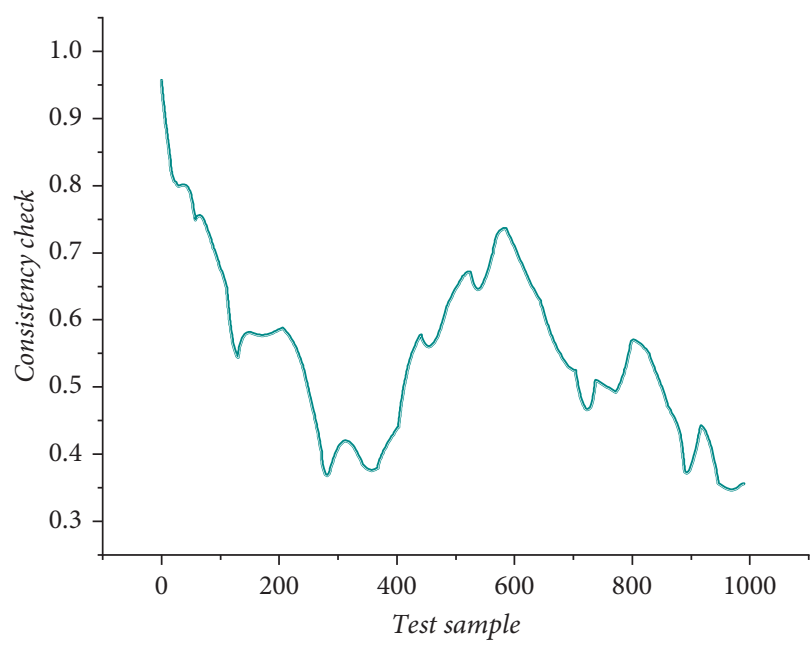

- Evaluation index A

(a)

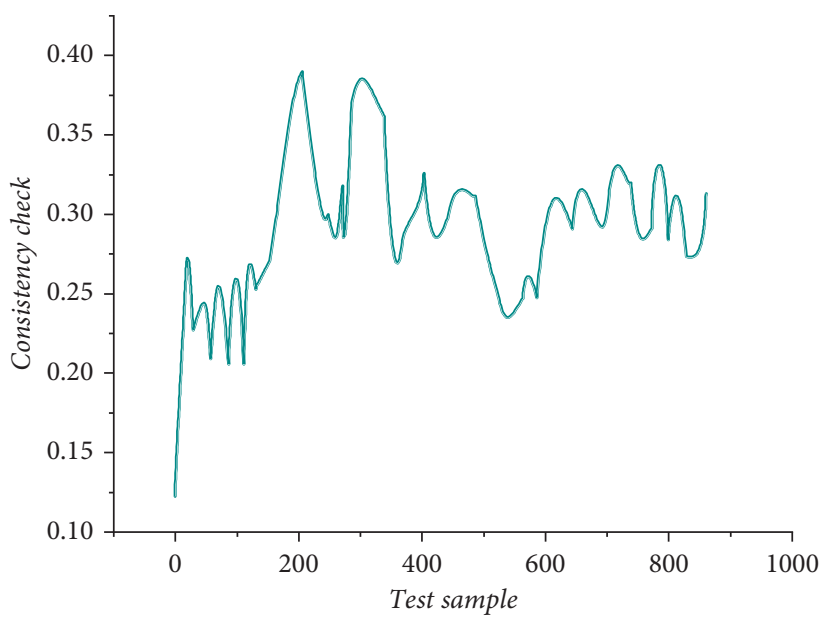

Evaluation index C

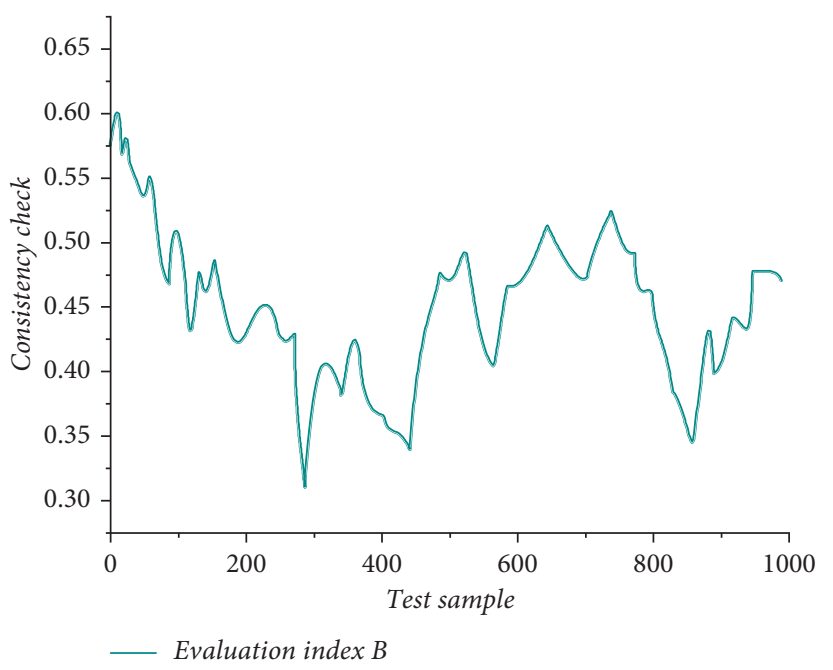

(b)

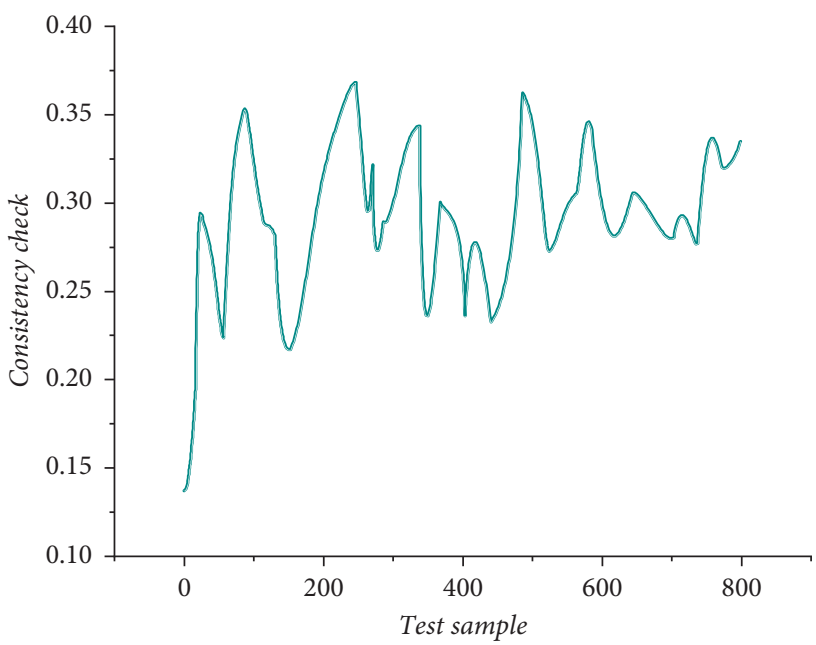

— Evaluation index D

(c)

(d)

FIGURE 4: Consistency test results of different evaluation indicators.

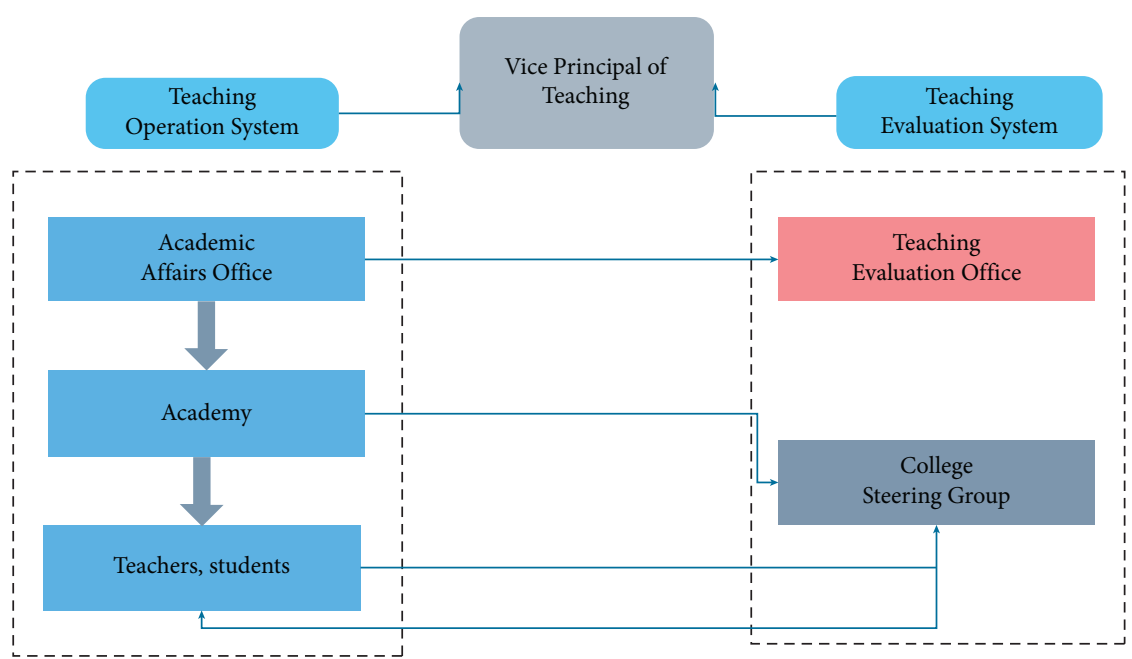

FIgURE 5: The collaborative cooperation model of "self-monitoring" and "other monitoring". 
cooperation of "white monitoring" and "other monitoring." In daily work, on the one hand, the teaching guidance group supervises, supervises, and guides the quality elements of the teaching process. We got feedback from the implementing agency of the teaching operation system. As an executive agency, the college takes timely measures to correct deviations based on the feedback information, to achieve dynamic monitoring of teaching quality in the process.

\section{Conclusion}

With the increasing standardization of teaching management, the role of teaching evaluation as a quality diagnosis and control method is becoming more and more important. Through evaluation, the school's teaching management can be promoted to be more scientific and standardized, which is the main measure and effective means of macrocontrol teaching. However, the current teaching evaluation index system used by schools mainly measures teachers' theoretical teaching levels. The existing teaching evaluation index system only focuses on explicit behavior. For example, the design, implementation, application, and promotion of the teaching evaluation index system only reflect superficial. This paper establishes an Internet of Things architecture to collect information on the impact indicators of the teaching evaluation process and builds a teaching evaluation index system. Through researching the index of teachers' teaching quality evaluation, the author designs more scientific indexes. On this basis, this article combines fuzzy comprehensive evaluation for the quantification and evaluation process of index information. Through comparative analysis, the program can provide an effective way to construct a teaching evaluation system suitable for applicationoriented undergraduate colleges. Of course, due to the rush of time and the limited level of research, many issues have not had time to think and study. Some research still needs to be tested by work practice, and the letter needs to be summarized and condensed rationally.

\section{Data Availability}

The data used to support this study are included within the manuscript.

\section{Conflicts of Interest}

The author declares that there are no conflicts of interest.

\section{Acknowledgments}

This research had been financed by the 13th Five-Year Plan of Guangzhou Philosophy and Social Sciences project in 2019 "Research on Organizational Change of Applicationoriented Institutes" (2019GZGJ193).

\section{References}

[1] A. D. Shellito, C. D. Virgilio, G. Lee et al., "Investigating association between sex and faculty teaching evaluation in general surgery residency programs: a multi-institutional study," Journal of the American College of Surgeons, vol. 231, no. 3, p. 309, 2020.

[2] N. J. Compton, J. A. Cary, J. R. Wenz, J. D. Lutter, C. F. Mitchell, and J. Godfrey, "Evaluation of peer teaching and deliberate practice to teach veterinary surgery," Veterinary Surgery, vol. 48, 2018.

[3] M. Hessler, D. Poepping, and M. Hollstein, "Availability of cookies during an academic course session affects the evaluation of teaching," Medical Education, vol. 52, 2018.

[4] L. Zhao and P. W. Wang, "Research and application of university biological specialty teaching quality evaluation model based on bp neural network," Basic and Clinical Pharmacology and Toxicology, vol. 118, no. 1, p. 80, 2016.

[5] S. M. Hejri, A. Mirzazadeh, and M. Jalili, "Peer observation of teaching for formative evaluation of faculty members," Medical Education, vol. 52, no. 5, 2018.

[6] C. L. Bradley, J. Khanova, and K. L. Scolaro, "Evaluation of a teaching assistant program for third-year pharmacy students," American Journal of Pharmaceutical Education, vol. 80, p. 149, 2016.

[7] D. Rosin, "Total extra-peritoneal hernia repair: residency teaching program and outcome evaluation," World Journal of Surgery, vol. 41, no. 1, pp. 106-107, 2017.

[8] C. A. Petrarca, J. Warner, A. Simpson, R. Petrarca, A. Douiri, and D. Byrne, "Evaluation of e-learning for the teaching of undergraduate ophthalmology at medical school: a randomized controlled crossover study," Eye, vol. 32, 2018.

[9] R. H. Stone, A. P. Bress, and E. A. Nutescu, "Upper-extremity deep-vein thrombosis: a retrospective cohort evaluation of thrombotic risk factors at a university teaching hospital antithrombosis clinic," The Annals of Pharmacotherapy, vol. 50, 2016.

[10] C.-L. Chiu, W.-T. Pan, and C. Huang, "Study on the performance evaluation of online teaching using the quantile regression analysis and artificial neural network," The Journal of Supercomputing, vol. 72, no. 3, pp. 789-803, 2016.

[11] M. H. Scharrer and M. J. Peterson, "Teaching decisional capacity evaluation," American Journal of Geriatric Psychiatry, vol. 26, no. 3, pp. S115-S116, 2018.

[12] V. C. Nikolian, C. P. Magas, J. Church et al., "Intraoperative observation and evaluation improves teaching and increases resident autonomy," Journal of the American College of Surgeons, vol. 223, no. 4, p. S128, 2016.

[13] A. Robinson-Perez, M. Marzell, and W. Han, "Racialmicroaggressions and psychological distress among undergraduate college students of color: implications for social work practice," Clinical Social Work Journal, vol. 48, no. 2, 2020.

[14] J. L. Bourdon, A. A. Moore, E. C. Long, K. S. Kendler, and D. M. Dick, "The relationship between on-campus service utilization and common mental health concerns in undergraduate college students," Psychological Services, vol. 17, no. 1, pp. 118-126, 2020.

[15] K. Nelwati, K. L. Abdullah, and M. C. Chong, "Factors influencing professional values among Indonesian undergraduate nursing students," Nurse Education in Practice, vol. 41, p. 102648, 2019.

[16] C. Xu, Y. Li, P. Chen, M. Pan, and X. Bu, "A survey on the attitudes of Chinese medical students towards current pathology education," BMC Medical Education, vol. 20, no. 1, p. 259, 2020.

[17] A. Bedaso, B. Duko, and T. Yeneabat, "Predictors of mental distress among undergraduate health science students ofHawass university, college of medicine and health sciences, 
Hawass, snnpr, Ethiopia: a cross-sectional study," Annals of General Psychiatry, vol. 19, no. 1, pp. 1-5, 2020.

[18] B. Vha, B. Gtce, C. Lap, D. Ogb, and A. Cags, "Internet of things in arable farming: implementation, applications, challenges, and potential - ScienceDirect," Biosystems Engineering, vol. 191, pp. 60-84, 2020.

[19] A. Aslam, U. Mehmood, M. H. Arshad et al., "Dye-sensitized solar cells (dsscs) as a potential photovoltaic technology for the self-powered internet of things (iots) applications," Solar Energy, vol. 207, pp. 874-892, 2020.

[20] J. Chauhan and P. Goswami, "An integrated metaheuristic technique based energy aware clustering protocol for internet of things based smart classroom," Modern Physics Letters B, vol. 34, no. 22, p. 2050360, 2020.

[21] L. Barolli, F. Hussain, and M. Takizawa, "Special issue on intelligent edge, fog, cloud and internet of things (iot)-based services," Computing, vol. 103, 2021.

[22] I. S. miri, J. Prakash, M. Balasaraswathi, V. Sivasankaran, and O. Henry, "Dabpr: a large-scale internet of things-based data aggregation backpressure routing for disaster management," Wireless Networks, vol. 26, no. 4, 2020.

[23] M. R. Mousavi, A. Shahzadi, and A. A. Orouji, "ICI analysis of hyperbolic FRFT-FBMC based on optimal order of transform for Internet of Things applications," IET Communications, vol. 14, no. 8, pp. 1209-1214, 2020.

[24] R. Abbasikesbi, A. Nikfarjam, and M. Nemati, "Developed wireless sensor network to supervise the essential parameters in greenhouses for the internet of things applications," IET Circuits, Devices and Systems, vol. 14, no. 8, pp. 1258-1264, 2020.

[25] Y. Zhu, L. A. Hao, and Q. A. Ping, "Heterogeneous teaching evaluation network-based offline course recommendation with graph learning and tensor factorization-ScienceDirect," Neurocomputing, vol. 415, pp. 84-95, 2020.

[26] K. Schieder, R. R. Zsoldos, M. Dippel, C. Siedler, and T. F. Licka, "Use of physical self-experience for teaching lameness evaluation: short-term effects on lameness evaluation of horses with mild forelimb lameness by novice veterinary students," Journal of Veterinary Medical Education, vol. 47, no. 3, p. e0618079r, 2019.

[27] Q. Lin, Y. Zhu, S. Zhang, P. Shi, Q. Guo, and Z. Niu, "Lexical based automated teaching evaluation via students' short reviews," Computer Applications in Engineering Education, vol. 27, no. 1, pp. 194-205, 2019.

[28] R. Lawson, H. Géniaux, S. Bailly, C. Pouget, C. Fagnère, and M. L. Laroche, "Contributions of blended learning based on peer evaluation for teaching drug-drug interactions to undergraduate pharmacy students," BMC Medical Education, vol. 19, 2019.

[29] A. Abdelhadi and M. Nurunnabi, "Engineering student evaluation of teaching quality in Saudi Arabia," International Journal of Engineering Education, vol. 35, no. 1A, pp. 262-272, 2019.

[30] M. Chen, S. Wang, and A. Hanna, "319: medication use evaluation of intravenous levothyroxine at a 591- bed teaching hospital," Critical Care Medicine, vol. 48, 2020.

[31] S. Barbosa and H. Marin, "Web-based simulation- a tool for teaching critical care nursing," Revista Latino-Americana de Enfermagem, vol. 17, no. 1, pp. 7-13, 2019. 